\title{
AS DEMANDAS CONSERVADORAS DO MOVIMENTO ESCOLA SEM PARTIDO E A BASE NACIONAL CURRICULAR COMUM*
}

\author{
Elizabeth Macedo ${ }^{1}$
}

\begin{abstract}
RESUMO: $\mathrm{O}$ artigo busca entender como a emergência do movimento autodenominado Escola sem Partido (ESP) e de suas demandas conservadoras deslocam as negociaçóes políticas na elaboração da Base Nacional Curricular Comum. O argumento central é o de que as negociaçóes em curso seguem pondo em funcionamento uma normatividade neoliberal, entendida em matriz pós-estrutural. São analisados a segunda versão da base e os sites de divulgação do ESP, tendo por pano de fundo a assunção pós-fundacional de que a política é uma luta por significação de demandas particulares de diferentes grupos.
\end{abstract}

Palavras-chave: Política curricular. Diferença. Base nacional curricular comum. Neoliberalismo. Escola sem Partido.

\section{THe SCHOOL Without PARTY CONSERVATIVE DEMANDS AND THE COMMON CORE}

\begin{abstract}
This article seeks to understand how the emergence of the self-nominated social movement School without Party (SWP) and its conservative demands dislocate political negotiations on the establishment of a National Common Core Curriculum. The central argument is that the ongoing negotiations put into operation a neoliberal normativity, as understood via post-structural framings. The second version of the common core as well as the SWP reporting sites are analyzed against a backdrop of this post-foundational assumption: that politics is a struggle for significance of particular demands of different groups.
\end{abstract}

Keywords: Curriculum policy. Difference. Common core. Neoliberalism. School without Party Social Movement.

\footnotetext{
*Texto vinculado ao projeto de pesquisa "Currículo, subjetividade e diferença", financiado pelo CNPq e pela FAPERJ.

${ }^{1}$ Universidade do Estado do Rio de Janeiro, Programa de Pós-graduação em Educação - Rio de Janeiro (RJ), Brasil. E-mail: bethmacedo@pobox.com

DOI: 10.1590/ES0101-73302017177445
} 


\section{LES DEMANDES CONSERVATRICES DU MOUVEMENT « École SANS PARTI » ET la BASE CoMmune POUR L'ÉLABORATION DU CURRICULUM NATIONAL}

RESUMÉ: Cet article cherche à comprendre comment l'émergence du mouvement social auto-désigné " Ecole sans Parti " (ESP) et ses demandes conservatrices disloquent les négociations politiques sur la mise en place d'une base commune pour l'élaboration du Curriculum National. L'argument central est que les négociations en cours continuent à mettre en service une normativité néolibérale, tel qu'il est compris par la matrice post-structurale. La deuxième version de la base ainsi que les sites de diffusion de l'ESP sont analysés dans un contexte de cette hypothèse post-fondationnelle : que la politique est une lutte pour la signification des exigences particulières de différents groupes.

Mots-clés: Politique du curriculum. Différence. Base commune pour l'élaboration du curriculum national. Néolibéralisme. Mouvement École sans Parti.

\section{Introdução}

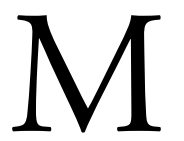

eu foco neste texto é entender as negociaçóes políticas em curso na elaboração da Base Nacional Curricular Comum (BNCC) com a entrada em cena de outro agente, qual seja, o movimento que se autodenomina Escola sem Partido (ESP). Surgido em 2004, ele se define como "uma iniciativa conjunta de estudantes e pais preocupados com o grau de contaminação político-ideológica das escolas brasileiras, em todos os níveis: do ensino básico ao

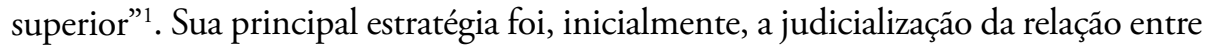
professores e alunos, tendo, em seguida, passado a pressionar as assembleias estaduais e municipais por projetos de leis que legitimassem suas ideias, processo que vem se intensificando. Como resultado dessa pressáo, tramitam na Câmara e no Senado Federal, desde 2015 e 2016, respectivamente, projetos de lei que alteram a Lei de Diretrizes e Bases da Educação Nacional (LDB) de modo a nela inserir um "programa escola sem partido"2 (BRASIL, 2015a; 2016b). Os vínculos dos projetos com o movimento são explicitados nos próprios projetos de lei e a aposta numa relação antagônica entre professores e alunos e pais segue sendo a tônica dos documentos. Em ambos os projetos, incita-se as secretarias de educação a criarem "um canal de comunicação destinado ao recebimento de reclamaçóes relacionadas ao descumprimento desta Lei, assegurado o anonimato" (BRASIL, 2015a; 2016b).

A tentativa de interferência do movimento ESP na política educacional tem-se dado em diferentes frentes. Não é meu objetivo, neste texto, entender a sua atuação política nas esferas em que isso ocorre nem o processo político que levou 
à sua criaçáo. Sequer tratarei explicitamente dos projetos de lei em andamento na Câmara e no Senado ou dos projetos estaduais, alguns já aprovados, que constituem as principais conquistas do movimento até agora. Isso tem sido feito por diferentes pesquisadores (PENNA, 2016; SOUZA et al. 2016; REIS et al., 2016). Meu foco será o currículo, mais especificamente os pronunciamentos do ESP sobre a BNCC elaborada pelo Ministério da Educação (MEC) e cuja segunda versão foi divulgada em 2016. Não se pode dizer que houve interferência do ESP nessa elaboração, mas sua presença nos debates vem se intensificando.

Assumo, pela agenda que o próprio ESP criou para si - "combate a uma mentalidade progressista, favorável ao PT, que auxiliou a manutenção deles no poder"; à "desqualifica(ção) (d)a religião; e "à naturaliza(ção) (d)o comportamento homossexual" (NAGIB apud RESENDE, 2015) ${ }^{3}$ —, que se trata de um movimento conservador que busca mobilizar princípios religiosos, a defesa da família em moldes tradicionais e a oposição a partidos políticos de esquerda e de origem popular. O que me interessa, neste texto, é como tal agenda se articula com os discursos circulantes no debate político sobre a BNCC. Em estudos anteriores (MACEDO, 2014; 2015; 2016), mapeei demandas em jogo na elaboração da BNCC, destacando como hegemonizam certo sentido de currículo e de educaçáo.

Com base na teoria do discurso (Laclau, 2011), trabalhei, em tais ocasiôes, com duas cadeias de demandas, geralmente antagônicas, que nomearei, neste texto, como demandas neoliberais por accountability e demandas críticas por justiça social. Tais termos condensam sentidos múltiplos que resumirei mais adiante; funcionam como metáforas (Laclau, 2011), ou seja, como condensaçóes de vários sentidos e significações. Tenho argumentado que tais demandas, apesar de manterem certo antagonismo em diferentes embates, têm, na discussão da BNCC, se articulado em oposiçáo à imprevisibilidade da ação docente e em defesa do controle do currículo (MACEDO, 2015; 2016). Há zonas de equivalência entre elas, o que não significa dizer que não há também diferenças. Como defende a teoria política do discurso (Laclau, 2008; 2011), a hegemonia se produz pela articulação de demandas distintas que se tornam equivalentes, nunca iguais, pela oposição a um exterior que a constitui. Nesse processo, as demandas particulares são - umas mais, outras menos - ressignificadas e obrigadas a abrir mão de suas especificidades. Nesse sentido, entendo que tanto as demandas neoliberais por accountability quanto as demandas críticas por justiça social vêm tensionando uma a outra na negociação, sem deixar de destacar a maior força das demandas neoliberais nesse processo. Como a entrada em cena das demandas conservadoras do ESP vem deslocar os acordos entre essas cadeias de demandas é o que me interessa neste texto.

Meu argumento é o de que a definição de uma BNCC é parte do funcionamento de uma normatividade neoliberal entendida como "uma forma peculiar de razão que configura todos os aspectos da existência em termos econômicos" (BROWN, 2015, p. 17). Entendo que a entrada em cena das demandas conservadoras do ESP desloca ainda mais o jogo político no sentido do controle que exclui a diferença, 
ao mesmo tempo em que torna explícita essa exclusão. Guia minha argumentação o compromisso com a defesa de que educação e currículo estão diretamente imbricados com a diferença como tal, assim como das conquistas — poucas ainda — dos diferentes grupos sociais que lutam por representação na esfera pública.

\section{Revisitando as demandas: a segunda versão da Base Nacional Curricular Comum}

Tenho partido da compreensão de que as articulações políticas para a definição de uma base comum para o currículo são responsáveis não apenas pela proposição de um currículo nacional, mas também por criar a sua própria necessidade. Em um nível ainda mais profundo, a naturalização de tal necessidade repousa e ajuda a instaurar um sentido para currículo, restringindo a multiplicidade abarcada pelo termo na literatura nacional e internacional. Tal literatura registra que não há estudos conclusivos dos impactos de currículos nacionais seja sobre a qualidade da educação oferecida, seja sobre a redução das desigualdades e a ampliação da justiça social (RAVITCH, 2013; SAHLBERG, 2015).

Também no Brasil o debate é antigo e retomá-lo, em suas descontinuidades, foge ao meu objetivo. Interesso-me pelas articulaçóes recentes que produziram as duas versóes do documento denominado BNCC, ciente de que elas reiteram, de forma produtiva, outras muitas articulaçóes levadas a cabo ao longo de muitos anos, envolvendo demandas de múltiplos atores sociais. Em texto anterior (MACEDO, 2014), mapeei as demandas que disputaram espaço no processo político que tornou hegemônica a ideia de que uma base comum era necessária - fazendo-a parte do Plano Nacional de Educação (PNE) - e que atuaram fortemente nos primeiros movimentos de redação da BNCC. Apoiada na metodologia de etnografia das redes, utilizada por Ball (2012) no estudo das políticas educativas, mapeei redes de governança envolvendo agentes públicos e privados - MEC, Uniáo Nacional dos Dirigentes Municipais de Educação (UNDIME) e Conselho Nacional de Secretários de Educaçáo (CONSED), movimentos sociais e acadêmicos, movimentos como o Todos pela Educação, grupos educacionais privados como o Centro de Estudos e Pesquisas em Educaçáo, Cultura e Ação Comunitária (CENPEC), a Fundação Victor Civita, o Instituto Ayrton Senna e fundaçóes ligadas a empresas como Natura, Gerdau, Itaú e, principalmente, a Fundação Lemann. Tal mapeamento permitiu perceber o que Ball (2012, p. 106) tem descrito como "acordo político do pós-estado da Providência". Para o autor, vivemos uma reterritorializaçáo das políticas que cria "comunidades políticas" (BALL, 2012, p. 5) descentradas. O núcleo estável das articulaçóes dessas comunidades é o antagonismo e, ao mesmo tempo, a dependência entre Estado e mercado, que produz "novas narrativas sobre o que conta como boa política" (BALL, 2012, p. 6).

Usando a teoria do discurso (LACLAU, 2011), propus que a estrutura significante "base curricular comum/qualidade da educação" funcionou como aglu- 
tinador de demandas de comunidades políticas distintas. Tal aglutinaçấo tornou-se possível pela expulsão do que denominei "a imprevisibilidade do chão da escola", que funcionou como exterior que hegemonizou a estrutura "base/qualidade". Tal imprevisibilidade poderia também ser denominada "cotidiano da escola" ou, como argumentarei mais tarde, "as demandas de grupos minoritários por representação no currículo e na sociedade". Como toda articulação em torno de um significante nodal, esta não apagou as diferenças entre as demandas, ainda que todas elas tenham perdido parte de suas especificidades com vistas à articulação. A leitura da primeira versão da BNCC (BRASIL, 2015b), assim como das versões preliminares que não chegaram a ser amplamente divulgadas (BRASIL, 2014b), deixa claro que, na luta por significação da base, as cadeias articuladas voltam a explicitar certo antagonismo.

Em estudos posteriores (MACEDO, 2015; 2016), mapeei duas cadeias de demandas articuladas, assim como as persistentes diferenças entre elas que tornam possível e dinâmica a articulação. Neste texto, estou denominando tais cadeias como "neoliberal por accountability" e "crítica por justiça social". A opção por antepor à accountability e à justiça social — os significantes que nucleiam cada uma delas — os termos neoliberal e crítica visa tornar mais explícitos os grupos de poder que se constituem por tais demandas e, de certa forma, restringir os sentidos dos significantes. Assim, o termo accountability, que tem uma longa história e mesmo a possibilidade de reapropriações democráticas (AFONSO, 2012), é significado a partir do adjetivo neoliberal em sua acepção clássica, envolvendo os pilares da avaliação, da prestação de contas e da responsabilização ${ }^{4}$. Em relação às demandas por justiça social, este tem sido um conceito caro ao pensamento crítico que "abarca uma concepção ampla de questôes de equidade, oportunidade e justiça”" (BALL apud MAINARDES; MARCONDES, 2009, p. 308) e permite articular as demandas de "raça, classe, deficiência ou sexualidade" (BALL apud MAINARDES; MARCONDES, 2009, p. 308). Ainda que ambas as cadeias de equivalências sejam recriadas ao longo dos jogos políticos de articulação - produzindo deslizamentos entre um momento e outro desses jogos —, tenho argumentado em torno de certa estabilidade dessas demandas e dos grupos que as articulam no debate recente da BNCC.

Neste texto, tomo um momento específico do processo político em tela, qual seja, a elaboração da segunda versão do documento, realizada em meio a uma avaliação muito negativa, e generalizada, da versão anterior. Mesmo grupos que demandam uma definição curricular nacional tenderam a fazer críticas ao conteúdo e, por vezes, à forma da primeira versão disponibilizada. Ambas as versóes estão organizadas a partir de dois significantes que se hegemonizaram durante a elaboração do PNE: direitos e objetivos de aprendizagem e ensino (BRASIL, 2014a). A primeira parte da segunda versão do documento explora a ideia de direitos de aprendizagem e desenvolvimento como norteadora da BNCC. A segunda, por sua vez, apresenta um conjunto de objetivos por componente curricular e ano de escolarização, em média 10 a 25, mas podendo chegar, como no caso da língua portuguesa, a 40 objetivos por ano. Embora, explicitamente, o texto da base bus- 
que uma articulação entre as partes ao informar que "as concepções de direito de aprendizagem e desenvolvimento são, portanto, balizadoras da proposição dos objetivos de aprendizagem para cada componente curricular" (MEC, 2014a, p. 33), não se percebe facilmente o vínculo reivindicado.

Para além de buscar exemplos tópicos de desarticulação, opto por caracterizar as duas cadeias de sentidos que produzem, de um lado, o discurso dos direitos e, de outro, uma listagem de objetivos. Tomo essa dupla inscrição como expressáo das lutas entre demandas críticas por justiça social e demandas neoliberais por accountability por preencher o sentido de base comum nacional. Apesar de considerar que há luta política na significação de ambos os significantes, defendo que a própria valorização de um ou de outro, nos documentos, expressa o fortalecimento de uma das cadeias de demandas nessas lutas. Lembro, em defesa dessa tese, que o termo "direitos de aprendizagem e ensino" substituiu a expressão "expectativas de aprendizagem" na formulação do PNE, com o argumento de que esta última "reforçava noções de performatividade e de competências [...] e regulação [...] por meio da fixaçâo de metas mensuráveis [...], mecanismos de prestação de contas e incentivo a comparaçôes e a competições" (apud Macedo, 2015, p. 893).

O termo "direitos" foi, portanto, apresentado por entidades representativas da área de educação - Associação Nacional de Pós-Graduação e Pesquisa em Educação (ANPEd), Associação Nacional pela Formação dos Profissionais da Educação (Anfope), Associação Nacional de Política e Administração da Educação (Anpae), Centro de Estudos de Direito Econômico e Social (Cedes), Confederação Nacional dos Trabalhadores em Educação (CNTE) e Campanha Nacional pelo Direito à Educaçáo - como um antídoto à hegemonia das demandas por accountability. A força dessas entidades na luta pelo significante e por seu preenchimento é admitida na própria BNCC, em sua segunda versão: "Os movimentos sociais têm importante papel na definição dos direitos de aprendizagem e desenvolvimento que fundamentam a elaboração da BNCC” (BRASIL, 2016a, p. 27).

Em linhas gerais, os direitos foram definidos como "fundamentais à aprendizagem e ao desenvolvimento, com os quais o trabalho que se realiza em todas as etapas da Educação Básica deve se comprometer" (BRASIL, 2016a, p. 33). Nessa acepção, os direitos se "explicitam em relação aos princípios éticos, políticos e estéticos [...] que devem orientar uma (determinada) Educação Básica” (BRASIL, 2016a, p. 33). Na lista de direitos que se "afirmam em relação" (BRASIL, 2016a, p. 34) aos diferentes princípios, no entanto, observa-se um elenco de direitos, que devem ser garantidos aos estudantes, que não se caracterizariam como "direitos [...] de aprendizagem e desenvolvimento aos quais todas as crianças, adolescentes e jovens brasileiros devem ter acesso ao longo de seu processo de escolarização" (BRASIL, 2016a, p. 44).

Entendo que, na segunda versão da BNCC, esses direitos ganham mais centralidade e sua definição explicita, na comparação com a primeira versão, uma 
guinada de maior comprometimento do texto com as demandas críticas por justiça social. São diversos os exemplos dessa guinada, como o uso que passa a fazer do termo "cidadania": "A educação, compreendida como direito humano, individual e coletivo, habilita para o exercício de outros direitos, e capacita ao pleno exercício da cidadania” (BRASIL, 2016a, p. 26). Diversidade, inclusão, direitos humanos também se alternam na caracterização dos direitos de aprendizagem e ensino. Por fim, retorna o significante "conhecimento", tomado na matriz crítica - como historicamente construído ou como construção social — e, de forma mais pontual, o significante "trabalho". Entendo que tal conjunto explicita um dos campos hegemônicos na formulaçáo do documento, o do pensamento crítico, sem dúvida importante por sua força no discurso pedagógico pós-ditadura. Tal pensamento esteve muito presente no início da discussão da BNCC — desde o programa Currículo em Movimento, em que currículo era definido como "constituído pelas experiências escolares que se desdobram em torno do conhecimento" (MOREIRA; CANDAU, 2009, p. 45) e perdeu espaço ao longo do processo, até ressurgir na retórica de explicitação dos direitos de aprendizagem e desenvolvimento, nessa segunda versão. Lembro, para sustentar essa posição, da presença de Michael Young nos seminários iniciais e das muitas referências que a ele se faziam (MACEDO, 2014) e que foram rareando.

Não me interessa aqui analisar se os direitos elencados são ou não relevantes. Em outro lugar, em relação aos da primeira versão (MACEDO, 2015), argumento que a própria ideia de direito mantém certo vínculo com accountability, na medida em que opera com um sujeito abstrato em contraposição àquele que se produz no agonismo (MOUFFE, 2003). Ademais, a própria justificativa da definição desses direitos subjetivos está marcada pela linguagem da cobrança de que os direitos sejam garantidos a todas as crianças. Aqui, desejo apenas evidenciar, na imprecisão do termo e na guinada crítica, uma disputa por sua significação. Por um lado, a importância de mantê-lo; por outro, a dificuldade de significá-lo.

$\mathrm{Na}$ segunda parte do documento, as demandas por accountability ganham mais visibilidade. Essa parte permanece estruturada por áreas de conhecimento e disciplinas, e o diálogo preferencial se faz com a literatura dos respectivos campos temáticos ou disciplinares. Novamente, é importante caracterizar que o termo "objetivos" não remete apenas a demandas por accountability: em não poucos casos, demandas críticas por justiça social estão presentes como preocupaçóes que norteiam a seleção e a organização dos objetivos. No entanto, do ponto de vista do currículo, está-se diante de uma tradição marcada pela racionalidade técnica, herdeira da administração científica, que congrega um conjunto de modelos de elaboração curricular cujo núcleo central é a relação entre a definição de objetivos de aprendizagem (ou ensino) e a avaliação de sua consecução (PINAR et al., 1995). Cito dois objetivos, ao acaso, que permitem observar, por um lado, seu descolamento dos direitos tal como descritos na primeira parte e, por outro, o quanto são instrumentais: "Reconhecer vistas ortogonais de figuras espaciais e aplicar esse conhecimento para desenhar objetos em perspectiva" (MT, 9 ano, p. 409); "Identificar e classificar alimentos e 
materiais de acordo com sua origem: animal, vegetal ou mineral, fazendo perguntas sobre como são produzidos" ( $\mathrm{CN}, 4^{\circ}$ ano, p. 287).

Em outro lugar (MACEDO, 2016), defendo que esse caráter instrumental opera com uma concepção pragmática de conhecimento - conhecimento para algo - que tem sido apontada por diversos autores, dentre os quais Labaree (1998), como a atualização das visóes técnicas de currículo. Por outro lado, o conhecimento epistemologicamente poderoso — que defino como "conhecimento em si" —, que tem sido defendido pelas demandas críticas por justiça social, não tem colidido com o instrumentalismo das demandas por accountability. Defendo (MACEDO, 2016) que isso ocorre porque as demandas críticas por justiça social, ao projetarem um sujeito abstrato, acabam por instrumentalizar o conhecimento. Embora o significante "objetivos" materialize demandas neoliberais por accountability, ele é reforçado, em sua luta por hegemonia, pelas demandas por justiça social.

Assim, o jogo político entre demandas críticas por justiça social e demandas neoliberais por accountability explicita afastamentos e aproximaçōes entre elas. Se nos acostumamos a vê-las como antagônicas, sugiro que a defesa da necessidade de uma base curricular em nível nacional — de um currículo com certo nível de universalidade — as tem aproximado, criando equivalências.

\section{A entrada do Escola sem Partido na cena da Base Nacional Curricular Comum}

Já com a segunda versão da BNCC divulgada, um novo conjunto de demandas, que chamarei de "demandas conservadoras", tem se fortalecido. Náo que elas não estivessem presentes em todo o processo, como ocorre em nível internacional, mas ganharam proeminência após o impeachment de Dilma Rousseff, quando o ESP passou a ser um dos interlocutores do $\mathrm{MEC}^{5}$. Em forte associação com deputados da bancada evangélica neopentecostal - que a partir dos anos 1980 têm lutado por representação política e a ampliado (BURITY, 2015) —, o ESP inseriu em sua agenda o debate sobre a BNCC.

O movimento apresenta duas ordens de demandas em relaçáo à BNCC: quanto à instância competente para sua aprovação e quanto ao seu conteúdo, mais especificamente, aos objetivos de aprendizagem e ensino. Ao pôr em xeque a competência do Conselho Nacional de Educação (CNE) e do MEC para a definição da BNCC, o movimento tem sustentado que a organização do documento em torno de direitos de aprendizagem, preconizada pela lei que instituiu o PNE, é "invasão de competências". Para ele, a BNCC tem "que tratar de currículo, não de direitos. Porque os direitos estão contidos na Constituição. O documento propõe novos direitos" ${ }^{\text {"6 }}$. Com argumento semelhante, reivindica-se a alteração da instância de aprovação da BNCC do CNE para o Congresso Nacional: "Numa democracia, se alguém deve ter o poder de decidir o 
que é que dezenas de milhóes de indivíduos serão obrigados a estudar ao longo da sua vida escolar, que seja o parlamento, e não um punhado de agentes públicos indicados pelo chefe do Executivo. Cabe, pois, ao Congresso Nacional chamar a si, o quanto antes, essa imensa e histórica responsabilidade"7. Tal reivindicação pouco tem deslocado as relaçóes de poder até então estabelecidas no que tange às formas de significar a base curricular comum em nível nacional. Efetivamente, a oposição do ESP à competência do MEC para legislar sobre a BNCC tem rearticulado e aproximado os grupos envolvidos na luta política até então. Agentes públicos, como a UNDIME e o CONSED, assim como agentes privados, têm defendido não só a necessidade da BNCC, como o que foi feito até o momento. A fala da representante da Fundação Lemann explicita uma posição que parece francamente hegemônica em defesa da BNCC: "A Base é uma demanda da sociedade brasileira [...] A participação do Congresso é para mo-

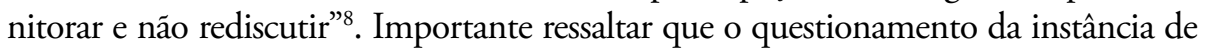
deliberação sobre a BNCC feito pelo ESP se refere mais especificamente aos direitos de aprendizagem e desenvolvimento, pouco se reportando aos objetivos em si. Parece haver acordo em que a "BNCC deve tratar de currículo", por isso entendendo-se uma listagem do que deve ser ensinado na escola: "Aquilo que, na perspectiva do constituinte de 1988, deveria ser um conjunto de conteúdos, se converteu num manual para homogeneizar cabeças e tornar hegemônica, no ambiente escolar, a ideologia que, há tempos, grassa e desgraça a educação brasileira” (PUGGINA, s.d.) ${ }^{9}$.

Ainda que os direitos de aprendizagem e ensino se assentem sobre uma noção abstrata de sujeito - seja na defesa de um genérico cidadão de direito (SCOTT, 2007), seja na leitura de uma cidadania de consumo (CANCLINI, 2006) — , esse significante ainda é o espaço privilegiado para as demandas críticas por justiça social. $\mathrm{O}$ ataque frontal e central do ESP aos direitos, no intuito de reduzir a BNCC a um conjunto de conteúdos a ser ensinado, desloca, potencialmente, o jogo político na direção do fortalecimento das demandas neoliberais por accountability.

No que concerne aos objetivos de aprendizagem e ensino, as demandas conservadoras podem ser resumidas, sem prejuízo dos argumentos levantados, em alguns pontos. Na página do ESP (http://escolasempartido.org), a defesa dessas demandas é subsidiada por um conjunto de exemplos de uma suposta doutrinação produzida via currículo, com o apoio da "burocracia do MEC e das secretarias de educação”, assim como dos meios de comunicação.

1. Em prol da separação entre espaço público e privado, transferindo a educação para o espaço privado da família, a quem caberia toda a formação moral e ética das crianças. $\mathrm{O}$ espaço público da escola é destinado ao aprendizado de conteúdos (Figura 1).

"Educar é promover na pessoa, sentimentos hábitos que lhe permitam adaptar-se no meio que há de viver. Instruir é proporcionar conhecimentos e habilidades, que permitam à pessoa ganhar o seu sustento." Armindo Moreira ${ }^{10}$. 
2. Contra o viés ideológico de esquerda que sustentaria o documento apresentado à consulta pública.

Não podemos ser ingênuos. Há um pensamento hegemônico da esquerda nas universidades e foram essas pessoas que majoritariamente construíram esse documento. ${ }^{11}$

É possível inferir a hegemonia da epistemologia marxista e do método crítico-cultural não somente na parte das ciências humanas, mas até mesmo nas chamadas ciências duras, até na matemática, em química, em física, em biologia. Quais as intençôes políticas e as consequências para o nosso futuro democrático como resultado dessa escolha? ${ }^{12}$

3. Contra a diversidade cultural nos currículos.

O último desabamento foi provocado pela proposta da Base Nacional Comum Curricular (BNCC). Dias atrás, o historiador Marco Antonio Villa demonstrou, em artigo publicado no jornal O Globo, que, se a proposta do MEC for aprovada, os estudantes brasileiros que quiserem aprender alguma coisa sobre o antigo Egito, a Mesopotâmia e a Grécia; o Império Romano e o nascimento do cristianismo; a Idade Média, o Renascimento, a Revoluçāo Industrial e até mesmo a Revolução Francesa serão obrigados a se virar por conta própria. $\mathrm{Na}$ sala de aula, teráo de estudar os mundos ameríndios, africanos e afrobrasileiros; interpretar os movimentos sociais negros e quilombolas; valorizar e promover o respeito às culturas africanas e afroamericanas. É um assombro. ${ }^{13}$

4. Contra a ideologia de gênero nos currículos.

Menos comentada, mas não menos importante, é a presença da famigerada ideologia de gênero. Como já se adivinhava, a perspectiva de gênero - cuja inclusão, nos planos de educaçáo, foi rejeitada de maneira veemente pela quase totalidade das nossas casas legislativas - atravessa toda a proposta do MEC. ${ }^{14}$

Escolas de SP acabam com "O Dia das Máes" e instituem o "Dia dos Cuidadores". Viva o fim da família, prefeito Fernando Haddad! ${ }^{15}$

\section{Figura 1}

Esquema apresentado pelo Escola Sem Partido ${ }^{16}$.

Vamos deixar de utilizar o termo educação ao nos referirmos ao ensino?

Educação $=$ Valores morais $\rightarrow$ Pais, Família .

Ensino/Instrução $=$ Conhecimentos e Habilidades $\rightarrow$ Professor, Escola . 
Esse conjunto de demandas conservadoras do ESP em relação ao "conteúdo" da BNCC é bastante pontual e aponta menos para o que deve fazer parte do currículo do que para o que deve ser excluído, para que a escola possa "atender a todos". As exclusóes citadas explicitamente se referem a demandas político-partidárias, raciais, de gênero e de sexualidade. $\mathrm{O}$ potencial dessas exclusōes para deslocar as articulaçóes sobre a BNCC é preocupante, na medida em que elas focam diretamente demandas de grupos minoritários — de raça, gênero e sexualidade que, ainda timidamente, têm conquistado algum espaço.

O próprio jogo político que levou a uma BNCC em que uma listagem de objetivos é entendida como necessária para que direitos de aprendizagem e ensino se materializem já embute uma série de exclusóes, ainda que não admitidas explicitamente. Para além da promessa de inclusividade nas seleçôes do que deve constar na BNCC, expressa-se que, por ela não corresponder à totalidade do currículo, outros conhecimentos podem ser acolhidos. O caráter excludente de toda seleção é, no entanto, insuperável, indo da óbvia aplicação de critérios cujas definições são políticas a formas discretas. Os critérios de seleção em disputa na BNCC remetem à empregabilidade, assim como ao maior poder de determinados conhecimentos do ponto de vista epistemológico (YOUNG, 2013). As demandas críticas por justiça social têm também incorporado as demandas de grupos minoritários por representação, ainda que elas sigam não ocupando lugar central no currículo. A exclusão proposta pelo ESP de tais demandas vem favorecer os critérios de seleção do eixo iluminismo-mercado, já hegemônicos.

$\mathrm{Na}$ linha de mecanismos mais sutis de exclusão, a ideia de que uma listagem de objetivos de ensino e aprendizagem definida em nível nacional é fundamental para garantir a qualidade da escola acaba reforçada pela defesa do ESP de que a função da escola é ensinar. Os direitos de cidadania ficam na dependência do domínio de algo externo ao sujeito, qual seja, conteúdos básicos que devem ser ensinados a (e aprendidos por) todos os alunos. Na medida em que tal domínio é uma operação individual, o fracasso que ele venha a produzir também o será: participar do todos é um direito que, uma vez garantido pela BNCC, só precisa ser aproveitado por cada um. Ou seja, a BNCC é apresentada como uma política para todos, e a exclusão que ela potencialmente promove é decorrência da ação individual daqueles que são excluídos.

Nesse sentido, avalio que as possíveis articulações entre a BNCC aí proposta e as demandas do ESP sáo preocupantes no momento, e me permito uma digressão sobre o fato de que o conservadorismo que o movimento traz parece ganhar espaço no mundo. Quando as demandas do ESP ampliam a exclusão seja de direitos, de objetivos ou de pessoas - e, mais do que isso, quebram a cordialidade com a qual ela vem sendo praticada na BNCC, o pesquisador de currículo não pode deixar de lembrar que, já na década de 1970, a vertente crítica da reconceptualizaçáo do campo ${ }^{17}$ perguntava a quem interessava que dado conhecimento fosse selecionado como mais válido (APPLE, 1982). Em estudo sobre a constituição do campo do currículo americano, Pinar $(2001 ; 2004)$ defende 
a tese de que há traumas constantemente revividos pela história americana que produzem um campo em que preconceitos de raça, gênero e sexualidade florescem. Minha questáo é o quanto o ESP ajuda a reviver, em nossa história, traumas de uma nação assentada no mito da inclusividade total erigido sobre a exclusão silenciosa do outro. A descortesia do ESP para tratar o diferente de si nos lembra a importância de retomar a (velha) questáo de Apple, o que farei nas bases pós-estruturais e pós-fundacionais em que venho construindo este texto.

\section{A normatividade neoliberal e a resposta sobre "a quem interessa"}

Retomo, pois, a questão nos termos em que julgo relevante e possível formulá-la: como funciona a normatividade a partir da qual se torna possível naturalizar que há um conhecimento mais válido para todos e que é possível defini-lo e torná-lo a base nacional para os currículos? Indo um pouco mais além, quais os efeitos dessa normatividade sobre a educação e a escola?

Em um termo que tenho evitado usar, pela forma reificada (COLLIER, 2011) com que vem sendo apropriado, vou nomear essa normatividade como neoliberal. De forma pouco pretensiosa, em diálogo com Brown (2015) e Dardot e Laval (2015), quero retomar uma leitura pós-estrutural da normatividade de forma a dar sentido ao meu argumento de que demandas tipicamente neoliberais por accountability podem se articular com demandas críticas por justiça social e, possivelmente, também com demandas conservadoras, fazendo funcionar a normatividade neoliberal. Seguindo Foucault, esse conjunto de autores defende que o neoliberalismo náo pode ser tomado como um universal, sendo constituído por um conjunto diferenciado de práticas.

O que caracteriza a normatividade neoliberal, para Brown (2015), assim como para Dardot e Laval (2015), é a economização da vida com a expulsão do político. Numa leitura bem livre, tanto da posição desses autores quanto da teoria do discurso (LACLAU, 2011) que venho utilizando neste texto, o político funciona como exterior constitutivo que estabiliza a fabulosa hegemonia do discurso neoliberal. A persistência dessa hegemonia ou o caráter normativo do discurso neoliberal, nos termos de Brown (2015), tem a ver com sua natureza performativa. A racionalidade neoliberal é posta em ação por sua própria repetição (ou citação).

A performatividade só é possível porque a citação é sempre distinta, ou seja, porque a reiteração está marcada, nos termos de Derrida, pela différance. Com isso, estou defendendo que o conjunto de estratégias que economizam a vida não é uma "motivação ideológica e intelectual" (DARDOT; LAVAL, 2015, p. 284). Embora global, não há um discurso neoliberal que preexiste às formas como ele se manifesta. A racionalidade neoliberal é "inconstante, diferenciada, assistemática, impura" (BROWN, 2015, p. 20), reconfigurada a cada iteração, e é exatamente tal reconfiguração que a póe em marcha. Dessa forma, os seus efeitos (deletérios 
ou não) não se relacionam diretamente ou apenas a uma ordem política e social (BROWN, 2015). Como norma, ela "toma forma como uma racionalidade de governo, estendendo uma formulação específica de valores, práticas e métricas para todas as dimensões da vida humana" (BROWN, 2015, p. 30). Seus efeitos nunca são determináveis ou mesmo previsíveis, posto que sua força está em seu caráter performativo, que requer iteração e différance.

A economização da vida que marca a normatividade neoliberal não está, para Brown (2015), atrelada à monetarização ou mesmo à marquetização, mas apenas indica que a "ordem semântica está mudando da política para a economia" (BROWN, 2015, p. 41). Nesse sentido, ela guarda aproximaçóes com o liberalismo, mas náo pode ser confundida com ele. Como aproximaçóes, apresenta os temas sociais "em termos de sua contribuição para o crescimento econômico e a [...] competitividade" (BROWN, 2015, p. 25); e subordina os compromissos do Estado "ao projeto de crescimento econômico, ao posicionamento competitivo e ao aumento do capital” (BROWN, 2015, p. 26). Mas o liberalismo clássico não propunha o fim do político, ainda que já "economizasse a política, a sociedade e o homem" (BROWN, 2015, p. 26). Assim como ocorria com o marxismo, tal liberalismo mantinha economia e política como campos em tensão. Para Brown (2015), a especificidade do neoliberalismo é que o homo economicus, definido como capital humano num modelo "de capital financeiro e de investimento" (BROWN, 2015, p. 33), "é tudo. Ele substitui [completamente] o homo politicus" (BROWN, 2015, p. 33).

É essa substituição total do homo politicus que quero retomar para pensar as articulaçóes em torno da defesa de uma base nacional comum para o currículo. Para além das diferenças entre as demandas neoliberais por accountability, as demandas críticas por justiça social e as demandas conservadoras, quero voltar às equivalências entre elas. Com base na teoria do discurso, vim definindo, aqui e em outros textos (MACEDO, 2014; 2015; 2016), o exterior constitutivo dessas equivalências como o imprevisível, o imponderável - o próprio antagonismo inerradicável, na linguagem dessa teoria, ou o homo politicus, nos termos de Brown (2015). O que se estabiliza ao expulsar o político - o lugar da diferença — é a normatividade neoliberal em seu movimento contínuo de valorização do homo economicus. Aqui, também, não é sem estranhamento que defendo que as demandas críticas por justiça social podem promover a normatividade neoliberal. Dardort e Laval (2015), no entanto, têm demonstrado como, no caso francês, justiça social e igualdade têm sido recalibradas para um lugar exclusivamente econômico. $\mathrm{O}$ inimigo do neoliberalismo não é uma ideologia política específica, mas o próprio "político, configurado como uma interferência indesejada” (BROWN, 2015, p. 42).

$\mathrm{Na}$ zona de equivalências entre as demandas que hegemonizam o discurso da BNCC, a própria ideia de que pode haver regras técnicas ou epistemológicas para responder ao que deve ser ensinado opera para a eliminaçáo do político com seus antagonismos. O ESP veio explicitar, pelo viés da intolerância ao outro, a inadequação do político na escola, o que leva a crer que ele encontra aí um amplo espaço 
possível de articulação. As demandas neoliberais por accountability e as demandas críticas por justiça social já vinham produzindo um consenso sobre conhecimentos necessários ao sujeito escolarizado, assim como um sentido para a escolarização ligado ao aprendizado de conhecimentos por seu valor intrínseco ou por sua utilidade para a participaçáo na vida social e econômica. Mesmo que de forma cordial, o universalismo, que precisa ser pressuposto para sustentar uma base nacional comum para os currículos, já escondia, sob a aparência de "neutralidade formal de contexto e conteúdo" (BROWN, 2015, p. 205), o seu caráter particular, sexista e racializado.

A eliminação do político é secundada, na BNCC, pela ideia de posse, outro pilar da normatividade neoliberal. A educação de qualidade envolve a aquisiçăo, pelo sujeito, de algo que lhe é externo, um conhecimento/comportamento capaz de torná-lo um "capital humano" ou, como diz Foucault (apud Brown, 2015), um "pequeno capital". Não é possível evitar que todo um histórico de despossessão de tal normatividade ecoe. Releio, aqui, a pergunta formulada por Butler e Anastasiou (2013) ao tratar das formas agressivas de privaçáo para pensar a necessidade de uma normatividade para a educação na forma do currículo. É possível pensar em formas éticas e políticas para que a educaçáo e os currículos atuem na luta por justiça social sem depender da valorização do individualismo possessivo? Com essa questão, quero defender que o engajamento efetivo contra a privaçáo forçada e coercitiva é também uma preocupação de uma teoria política pós-estrutural e pós-fundacional ${ }^{17}$. Ela apenas busca operar com um quadro complexo em que a normatividade que priva náo deixa imune um sujeito externo que a ela pode se contrapor. Se assim fosse, talvez já tivéssemos sido bem-sucedidos em nossas tentativas (políticas e críticas) de derrotá-la.

A luta possível, a meu ver, é o trabalho incessante para retomar o político ou a diferença constitutiva que se tem tentado erradicar. Como têm demonstrado inúmeros autores, dentre os quais os que mobilizamos neste texto, o caráter produtivo do poder faz com que pipoquem potencialidades subversivas aqui e ali quando qualquer norma é posta em funcionamento. Como não se trata de um poder que está fora, produzido e posto em funcionamento por alguém, sua eterna ameaça é o fantasma que ele mesmo gesta. A imprevisibilidade que ele se movimenta para controlar, mas que está sempre lá, como o expulso que o constitui. Essa impossibilidade de saturação, no entanto, não torna a ação política desnecessária; ao contrário, torna-a incessante. A mesma ação performativa da norma que produz diferença produz também o controle das significaçóes — aliás, essa é a sua funçâo primeira, se assim se pode falar. A luta política diuturna é por esburacar esse controle, deixando emergir os sentidos que ele quer excluir.

É o compromisso político com formas éticas e políticas de lutar pela justiça social que me leva a explicitar mais uma vez, neste texto, minha posiçáo contrária à formulação de bases comuns para o currículo em escala nacional. Entendo que os instrumentos normativos são uma tentativa de controle da imprevisibilidade em suas múltiplas formas de existir e devem se restringir àqueles que não podemos evitar. 
Mesmo que tenha certeza de que, como toda norma, esta não será capaz de controlar todos os seus efeitos, julgo que é preciso perturbar a certeza que se quer instaurar de que se pode economizar a vida e os corpos dos sujeitos, como se fossem "pequenos capitais". Ao buscar entender as dinâmicas constitutivas da hegemonia da ideia de que uma BNCC é necessária, tenho a esperança de colaborar para o desenvolvimento de alternativas que apostem numa escola em que, valorizadas, as relaçóes intersubjetivas de corpos possam esgarçar a normatividade que aqui chamei de neoliberal.

\section{Notas}

1. Disponível em: <http://www.escolasempartido.org/quem-somos $>$. Acesso em: 24 jul. 2016.

2. O número de projetos em andamento na Câmara e no Senado Federal com teor semelhante é elevado. Destaco aqui apenas os projetos apresentados, na página do movimento, como diretamente a ele vinculados (www.programaescolasempartido.org).

3. Miguel Nagib foi o criador do movimento e tem sido uma figura-chave na formulação de seus princípios.

4. Embora os sentidos da cadeia de demandas sejam dados, de forma contingente, pelas articulaçóes que as vão constituindo, uma definição inicial de demandas neoliberais por accountability poderia ser aquela formulada por Afonso (2012, p. 472): "Uma forma hierárquico-burocrática ou tecnocrática e gerencialista de prestação de contas que, pelo menos implicitamente, contém e dá ênfase a consequências e imputaçóes negativas e estigmatizantes, as quais, não raras vezes, consubstanciam formas autoritárias de responsabilizaçâo de instituiçôes, organizaçôes e indivíduos”.

5. Um conjunto de exemplos tópicos sustenta essa afirmativa. (i) em Seminário na Câmara dos Deputados em junho de 2016, com a presença de instâncias públicas e parceiros privados responsáveis pela elaboração da BNCC, a mesa que debateu as Ciências Humanas na base foi formada em sua totalidade por partidários do ESP (disponível em: < http://movimentopelabase.org.br/acontece/ comissao-educacao-camara-deputados-bnccl>. Acesso em: 15 jul. 2016); (ii) em julho de 2016, Adolfo Sachsida foi nomeado assessor especial do MEC, posiçáo revista em seguida. O economista é um dos principais defensores do ESP (disponível em: <http://g1.globo.com/educacao/noticia/ mec-desiste-de-nomeacao-de-apoiador-do-escola-sem-partido.ghtml>. Acesso em: 18 mar. 2017); e (iii) em março de 2017, representantes da bancada evangélica ligados ao ESP divulgaram a notícia de que a secretária-executiva do MEC "garante que ideologia de gênero não entrará na (terceira versão da) BNCC" (disponível em: < http://sostenescavalcante.com.br/mec-garante-que-ideologia-de-genero-nao-entrara-na-base-nacional-comum-curricular/>. Acesso em: 18 mar. 2017).

6. Deputado Rogério Marinho, autor do Projeto de Lei 1.411/15, na referida sessão da Câmara (disponível em: <http://www.epsjv.fiocruz.br/noticias/reportagem/escola-sem-partido-mira-na-base>. Acesso em: 15 jul. 2016).

7. Opiniáo de Miguel Nagib, na mesma sessão (disponível em: < $<$ http://www.escolasempartido.org/ artigos-top/576-quem-deve-aprovar-a-bncc>. Acesso em: 24 jul. 2016). 
8. Fala de Denis Mizne, representante da Fundação Lemann, na mesma sessão (disponível em: <http://www.epsjv.fiocruz.br/noticias/reportagem/escola-sem-partido-mira-na-base>. Acesso em: 24 jul. 2016).

9. Texto reproduzido na página do ESP.

10. Redação como no original. Disponível em: <http://escolasempartido.org/educacao-moral/ 415-professor-nao-e-educador>. Acesso em: 17 mar. 2017.

11. Deputado Rogério Marinho, em sessão já referida da Câmara dos Deputados (disponível em: $<$ http://www.epsjv.fiocruz.br/noticias/reportagem/escola-sem-partido-mira-na-base $>$. Acesso em: 15 jul. 2016).

12. Professor Orley Silva, na mesma sessão (disponível em: <http://www.epsjv.fiocruz.br/noticias/ reportagem/escola-sem-partido-mira-na-base $>$. Acesso em: 15 jul. 2016).

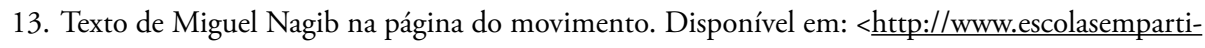
do.org/artigos-top/576-quem-deve-aprovar-a-bncc>. Acesso em: 24 jul. 2016.

14. Idem.

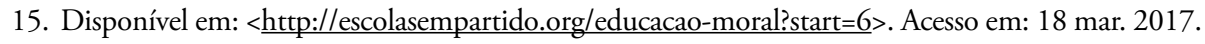

16. Página "Professor não é educador", direcionada a partir da página do movimento. Disponível em: <https://www.facebook.com/Professornaoeeducador>. Acesso em: 24 jul. 2016.

17. Ao retomar aqui a reconceptualização crítica, quero explicitar que as demandas que venho tratando como demandas críticas por justiça social, surgidas no jogo político que hegemoniza a ideia de base comum nacional para o currículo, não representam a totalidade do pensamento crítico. Em diferentes ocasiōes, Apple (1993) tem se posicionado contra a definição de currículos nacionais. O mesmo ocorre com outras tradiçôes críticas, como a pedagogia freireana, que sempre apostou na ação local.

18. Essa asserção expressa uma discordância entre autores como Thiesen (2015) e Fonte (2010) quando criticam as análises políticas pós-estruturais, acusando-as de desmobilizadoras.

\section{Referências}

AFONSO, A.J. Para uma conceitualização alternativa de accountability em educação. Educação e Sociedade, v. 33, n. 119, p. 471-484, abr./jun. 2012.

APPLE, M.W. Ideologia e Currículo. São Paulo: Brasiliense, 1982.

The politics of official knowledge: does a national curriculum make sense? Discourse, v. 14, n. 1, p. 1-16, out. 1993.

BALL, S.J. Global education Inc.: new policy networks and the neoliberal imaginary. New York: Routledge, 2012. 
BRASIL. Câmara dos Deputados. Projeto de Lei n. ${ }^{\circ}$ 867/2015. Brasília: Câmara dos Deputados, 2015a.

. Ministério da Educação. Base Nacional Comum Curricular: primeira versão. Brasília: MEC/SEB, 2015b.

- Ministério da Educação. Base Nacional Comum Curricular: segunda versão revista. Brasília: MEC, 2016a.

- Ministério da Educação. Planejando a próxima década: conhecendo as 20 metas do PNE. Brasília: MEC, 2014 a.

. Ministério da Educação. Por uma politica curricular para a educação básica. Brasília: MEC/SEB, 2014b.

. Senado Federal. Projeto de Lei n. ${ }^{\circ}$ 193/2016. Brasília: Senado Federal, 2016 b.

BROWN, W. Undoing the demos: Neoliberalism's stealth revolution. New York: Zone Books, 2015.

BURITY, J. Religião e espaço público: entrevista com Joanildo Burity, concedida a Lara Bonini e Thais Serafin. Debates do NER, Porto Alegre, v. 16, n. 28, p. 127-147, jul./dez. 2015.

Butler, J.; Anastasiou, A. Dispossession: the performative in the political. Cambridge: Polity, 2013.

CANCLINI, Néstor García. Consumidores e cidadãos: conflitos multiculturais da globalização. Rio de Janeiro: Editora da UFRJ, 2006.

COLLIER, S.J. Topologias de poder: a análise de Foucault sobre o governo político para além da "governamentalidade". Revista Brasileira de Ciência Politica, Brasília, n. 5, p. 245284, jul. 2011.

DARDOT, P.; LAVAL, C. Uma alternativa ao neoliberalismo: Entrevista a Daniel Pereira Andrade e Nilton Ken Ota. Tempo social, Sáo Paulo, v. 27, n. 1, p. 275-316, jun. 2015.

FONTE, S.S.D. Agenda pós-moderna e neopositivismo: Antípodas solidários. Educação e Sociedade, v. 31, n. 110, p. 35-56, jan./mar. 2010.

LABAREE, D.F. How to succeed in school without really learning. Yale: Yale University Press, 1998.

LACLAU, E. Emancipação e diferença. Rio de Janeiro: EdUERJ, 2011.

La razón populista. Buenos Aires: Fondo de Cultura Económica, 2008.

MACEDO, E. Base curricular comum: Novas formas de sociabilidade produzindo sentidos para educação. E-curriculum, v. 12, n. 3, p. 1530-1555, dez. 2014.

Base Nacional Comum para Currículos: direitos de aprendizagem e desenvolvimento para quem? Educação \& Sociedade, v. 36, n. 133, p. 891-908, dez. 2015.

. Base Nacional Curricular Comum: a falsa oposição entre conhecimento para fazer algo e conhecimento em si. Educação em Revista, v. 32, n. 2, p. 45-68, jun. 2016.

MAINARDES, J.; MARCONDES, M.I. Entrevista com Stephen J. Ball: um diálogo sobre justiça social, pesquisa e política educacional. Educação e Sociedade, v. 30, n. 106, p. 303-318, jan./abr. 2009. 
MATHEUS, D.S.; LOPES, A.C. Sentidos de qualidade na política de currículo (20032012). Educação e Realidade, Porto Alegre, v. 39, n. 2, p. 337-357, jun. 2014.

MOREIRA, A.F.B.; CANDAU, V.M.F. Indagações curriculares: currículo. Brasília: MEC, 2009.

MOUFFE, C. La paradoja democrática. Barcelona: Gedisa, 2003.

PENNA, F.A. Programa Escola sem Partido: Uma ameaça à educação emancipadora. In: GABRIEL, C.T.; MONTEIRO, A.M.; MARTINS, M.L.B. (Orgs.). Narrativas do Rio de Janeiro nas aulas de história. Rio de Janeiro: Mauad, 2016. p. 43-58.

PINAR, W. The Gender of Racial Politics \& Violence in America. New York: Peter Lang, 2001. What is curriculum theory? New York: Routledge, 2004.

Pinar, W.F. et al. Understanding curriculum. New York: Peter Lang, 1995.

PUGGINA, P. Totalitarismo através da educação. [s.d.]. Disponível em: <http://escolasempartido. org/artigos-top/578-totalitarismo-atraves-da-educacao $>$. Acesso em: 18 mar. 2017.

RAVITCH, D. Reign of error: the hoax of the privatization movement and the danger to America's public schools. New York: Random House, 2013.

REIS, G.R.F.S.; CAMPOS, M.S.N.; FLORES, R.L.P. Currículo em tempos de Escola sem Partido: Hegemonia disfarçada de neutralidade. Revista Espaço do Currículo, v. 9, n. 2, p. 200-214, maio/ago. 2016.

RESENDE, L. Escola sem partido quer fim da "doutrinação de esquerda”. O Dia, 06 set. 2015. Disponível em: <http://odia.ig.com.br/noticia/brasil/2015-09-06/escola-sempartido-quer-fim-da-doutrinacao-de-esquerda.html>. Acesso em: 24 jul. 2016.

SAHLBERG, P. Finnish Lessons 2.0. Nova York: Teachers College Press, 2015.

SCOTT, J.W. The politics of the veil. New Jersey: Princeton University Press, 2007.

SOUZA, A.L.S. et al. A ideologia da Escola sem Partido: 20 autores desmontam o discurso. Sáo Paulo: Autores Associados, 2016.

THIESEN, J.S. Virada epistemológica do campo curricular: Reflexos nas políticas de currículo e em proposiçôes de interesse privado. E-curriculum, São Paulo, v. 13, n. 4, p. 641-659, out./dez. 2015.

YOUNG, M.F. Overcoming the crisis in curriculum theory: a knowledge-based approach, Journal of Curriculum Studies, v. 45, n. 2, p. 101-118, abr. 2013.

Recebido em 22 de março de 2017.

Aprovado em 02 de abril de 2017. 